\title{
Performance of administrative case definitions for depression and anxiety in inflammatory bowel disease
}

Ruth Ann Marrie, MD, PhD ${ }^{1,2}$; John R. Walker, $\mathrm{PhD}^{3,4}$; Lesley A. Graff $\mathrm{PhD}^{3,4}$; Lisa M. Lix ${ }^{2}$; James M. Bolton $\mathrm{MD}^{5,6}$; Zoann Nugent, $\mathrm{PhD}^{3}$, Laura E. Targownik, MD, MSHS ${ }^{1,4}$; Charles N Bernstein $\mathrm{MD}^{1,4}$ for the CIHR Team "Defining the burden and managing the effects of psychiatric comorbidity in chronic immunoinflammatory disease"

\section{Running title: Administrative definitions of depression and anxiety in IBD}

1. Department of Internal Medicine, University of Manitoba, Winnipeg, Canada

2. Department of Community Health Sciences, University of Manitoba, Winnipeg, Canada

3. IBD Clinical and Research Centre, University of Manitoba, Winnipeg, Canada

4. Department of Clinical Health Psychology, University of Manitoba Winnipeg Canada

5. Manitoba Centre for Health Policy, Winnipeg, Canada

6. Department of Psychiatry, University of Manitoba, Winnipeg, Canada

Title: 103 characters

Abstract: 247

Text: 3002

Tables: 6

Figures: 0

Supplemental Figures: 2

References: 28

Study Funding: This study was funded by the Canadian Institutes of Health Research (THC-135234), a Don Paty Career Development Award from the MS Society of Canada (to RAM), and the Bingham Chair in Gastroenterology (to CNB).

Corresponding Author:

Charles N Bernstein

804F-715 McDermot Avenue,

Winnipeg, Manitoba, Canada

R3E3P4

Charles.bernstein@umanitoba.ca

Telephone: 2047893369

FAX: 2047893972 


\begin{abstract}
Objectives: Comorbid depression and anxiety are common in inflammatory bowel disease (IBD), but few population-based estimates of the burden of depression and anxiety exist. Methods to support population-based studies are needed. We aimed to test the performance of administrative case definitions for depression and anxiety in IBD and to understand what the prevalence estimated using such definitions reflects.
\end{abstract}

Methods: We linked administrative (health claims) data from the province of Manitoba, Canada with clinical data for 266 persons in the Manitoba IBD Cohort Study. We compared the performance of administrative case definitions for depression and anxiety with (a) diagnoses of depression and anxiety as identified based on the Composite International Diagnostic Interview (CIDI), which identifies disorders meeting formal diagnostic criteria, and (b) participant report of physician-diagnosed depression or anxiety.

Results: Administrative definitions for depression showed moderate agreement with the CIDI $(\kappa=$ 0.39-0.42). Agreement was higher with participant report of physician-diagnosed depression $(\kappa=0.54)$. The lifetime prevalence of depression was $29.3 \%$ based on the CIDI, $17.7 \%$ based on participant report of physician-diagnosed depression, and 21.8-22.5\% based on administrative data. Compared to the CIDI, administrative definitions for anxiety showed fair agreement $(\kappa=0.21-0.25)$. The lifetime prevalence of anxiety was $31.2 \%$ based on the CIDI, $9.7 \%$ based on participant report of physiciandiagnosed anxiety, and $24.4-31.9 \%$ based on administrative data.

Conclusions: Administrative data may be used for population-level surveillance of depression and anxiety in IBD, although they will not capture undiagnosed or untreated cases.

Key words: administrative data, anxiety, depression, inflammatory bowel disease, population-based, validation 


\section{Introduction}

Inflammatory bowel disease (IBD) is a chronic, immune-mediated disease of the gastrointestinal tract affecting over 4 million persons worldwide.(1) IBD includes Crohn's disease and ulcerative colitis, both of which are associated with medical comorbidities, including a higher risk for multiple sclerosis (MS) and inflammatory arthritis than the general population.(2) Psychiatric comorbidity is also common in IBD.(3) Depression may affect more than $25 \%$, and anxiety more than $30 \%$ of individuals with IBD over their lifetime.(4) Depression is associated with increased risks of disease relapse(5) and disability(6), and reduced quality of life. $(7,8)$ However, most studies evaluating the prevalence of psychiatric comorbidity in IBD have used clinic-based or small community samples. Large populationbased studies are needed to evaluate the incidence and prevalence of psychiatric comorbidities in IBD, and to assess their effects on outcomes.

Several approaches may be used to estimate the prevalence of depression and anxiety, including medical records review, self-report, and structured diagnostic interviews. However, these approaches can be resource-intensive for large studies. Administrative data from Canadian provincial health registries are population-based, cost-effective and accessible.(9) However, diagnostic accuracy can be variable depending on the accuracy and comprehensiveness of coding. Few published case definitions for psychiatric comorbidity have been validated, $(10,11)$ and those developed in the general population may not perform the same in a chronic disease population. Therefore, we aimed to test the performance of administrative case definitions for depression and anxiety in IBD and to gain an understanding of the validity of prevalence estimates using such definitions. 


\section{Methods}

\section{Administrative Data}

We conducted this study in the Canadian province of Manitoba, which had a population of approximately 1.28 million persons in 2014. Manitoba Health delivers universal, publicly funded health care for over $99 \%$ of residents, and maintains electronic datasets that capture health service delivery. We used data from the population registry, hospital discharge abstract database, physician services database, and Drug Program Information Network (DPIN) for the period of April 1, 1984 to March 31, 2014. The population registry records sex, region of residence (postal code), and dates of health care coverage, birth and death. The hospital discharge abstract database captures admission and discharge dates for all inpatient hospitalizations, and up to 25 discharge diagnoses. International Classification of Disease (ICD)-9 codes were used before 2004, and ICD-10-CA codes were used thereafter. Physician services claims capture the date of service, and a three-digit ICD-9-CM code for one physician-assigned diagnosis. DPIN captures all outpatient prescription drug dispensations for all residents including the date dispensed, drug name and drug identification number. These databases can be linked by a unique personal health identifier.

\section{Administrative Definitions of Depression and Anxiety}

Previously, we developed and tested multiple administrative case definitions for (i) depression, (ii) anxiety disorders, or (iii) depression and/or anxiety disorders, in a population with MS(12), another chronic immune-mediated disease with a high prevalence of depression and anxiety disorders. Based on the performance of the multiple definitions tested, we identified two sets of definitions that achieved 
the highest specificity while retaining moderate sensitivity. Generally as the number of claims required increased the specificity increased at the expense of sensitivity. The first set of definitions, labeled A, used only hospital and physician claims, whereas the second set of case definitions, labeled B, incorporated psychiatric medications in addition to diagnostic codes to improve specificity. The use of three-digit ICD-9 codes in physician claims confers a lack of specificity. For example, the code 300 describes anxiety states (300.0) and dysthymic disorder (300.4). Medications used for psychiatric comorbidities may be used off-label for other reasons(13) therefore we included only medications that were not used off-label for MS, and could not be used on or off-label for conditions other than psychiatric comorbidities unless we could exclude the condition using ICD codes (e.g. epilepsy). The case definitions require a specific number of health care encounters over a two-year period to identify the condition of interest with adequate specificity (Table 1). Once a person met the case definition he or she was considered affected in all subsequent years. The date of the first claim was considered the date of diagnosis.

\section{Clinical Reference Cohort}

The Manitoba IBD Cohort Study is a longitudinal study of health outcomes in an IBD cohort that began in 2002. Participants were recruited from the population-based University of Manitoba IBD Research Registry which included $\sim 50 \%$ of all persons with IBD in Manitoba as of 2000 . Participants in the registry had to be age $\geq 18$ years, and enrolled within 7 years of initial diagnosis (median: 4.3 years). Of 3,192 persons in the IBD registry when the cohort study was established, 606 (19.0\%) were eligible, of whom 388 enrolled. The demographic characteristics of enrollees were similar to that of the general IBD population of Manitoba.(14) Twenty-four months after enrollment (2003-2004) the remaining 351 participants underwent a structured psychiatric interview, the World Health 
Organization (WHO) Composite International Diagnostic Interview (CIDI). Based on this interview, we established the lifetime prevalence of depression (depression, dysthymia) and anxiety disorders (generalized anxiety disorder, social anxiety disorder, agoraphobia, panic disorder, obsessive compulsive disorder, post-traumatic stress disorder, specific phobia),(4) but could not determine if these disorders had been formally diagnosed or treated by a health professional.

In 2015, we contacted participants who had previously completed the CIDI to determine if they had ever been diagnosed with depression or anxiety by a physician ("Has a doctor ever told you that you have..."). Participants were interviewed by telephone using questions adapted from a validated comorbidity questionnaire.(15) If the participant gave an affirmative response, he or she was asked the year the condition was diagnosed, and if the condition had been treated by a physician in the last 10 years. Of the 351 in the study cohort, 266 had complete CIDI data, were successfully contacted in 2015, and had their telephone interview data linked to administrative data.

Sample Size and Power

A sample size of 140 is adequate to detect a kappa of $\geq 0.60$ (good agreement) for conditions with $\geq 10 \%$ prevalence, where the null hypothesis is that kappa $=0.40$ (moderate agreement), and alpha $=$ 0.05 and beta $=0.80$. Therefore, we expected that our clinical cohort $(\mathrm{n}=266)$ would provide adequate power to test these definitions.

Analysis 
Broadly, we compared the classification of depression and anxiety disorders according to the sets of administrative case definitions versus diagnoses of depression and anxiety disorders in the clinical cohort based on the CIDI and participant reports of physician diagnosis. As administrative data only capture health information for conditions for which care is sought through physicians or hospitalizations, we considered these case definitions to identify "diagnosed" depression or anxiety disorders for which treatment was sought, whereas the CIDI captured rates of clinical disorders for which treatment may or may not have been sought. These differences would be expected to reduce concordance between the data sources.(10) Therefore we defined the presence of depression or anxiety disorders, or both, in the reference clinical cohort in several ways: (i) CIDI-based diagnosis; (ii) participant report of physician diagnosis present at the time of the CIDI interview; (iii) participant report of physician diagnosis as of 2014; (iv) participant report of physician diagnosis as of 2014 and treatment in the prior 10 years (2004-2014). Participant reports were all obtained by follow-up telephone interview. For the first two comparisons we used administrative data from April 1, 1984 to the date of administration of the CIDI. For the third comparison we used administrative data from April 1, 1984 to the year of the participant reported physician diagnosis, while for the final comparison we used administrative data from April 1, 1984 to March 31, 2014 (latest date available).

For each comparison, we calculated Cohen's kappa $(\kappa)$ for chance-adjusted agreement; neither data source was considered the reference standard, and we interpreted results as slight $(0-0.20)$, fair $(0.21$ $0.40)$, moderate (0.41-0.60), substantial (0.61-0.80), and very good agreement (0.81-1.0).(16). Using conventional two-by-two contingency tables we also evaluated sensitivity, specificity, positive (PPV) and negative predictive value (NPV)(17) with 95\% confidence intervals (CI) for the administrative case definitions, as compared to the reference clinical cohort. To understand the effect of misclassification 
on our epidemiologic estimates, we used two approaches. First, we report the lifetime prevalence of depression or anxiety disorders according to the administrative case definitions and the four definitions drawn from the reference cohort. Second, we generated a series of 'true' prevalence estimates ranging from $0-100 \%$. We then applied the sensitivity and specificity values obtained for each administrative case definition to this series of true prevalence estimates in order to determine the number of true positives and false positives that would be observed. We summed the true positives and false positives to generate an observed prevalence. Then we graphed the 'true' prevalence estimates versus the expected value of observed prevalence. $(9,18)$ Statistical analyses were conducted using SAS V9.3 (SAS Institute Inc., Cary NC).

\section{Ethical Considerations}

This study was approved by the University of Manitoba Health Research Ethics Board and data access was approved by the Manitoba Health Information Privacy Committee.

\section{Results}

Of the 266 study participants, 164 (61.6\%) were women (Table 2), 52.6\% had Crohn's disease and most lived in urban areas.

\section{Depression}

As compared to a CIDI diagnosis of depression, the administrative definition depression-A had poor sensitivity (50.0\%) and good specificity (88.8\%) (Table 3). When compared to participant report of 
physician-diagnosed depression concurrent with the CIDI review period, sensitivity improved substantially to $76.6 \%$, with stable specificity (89.0\%). When the depression-B definition was used, the pattern of the findings was similar. Agreement between the administrative definitions and the various reference standards was moderate, although it was lowest with the CIDI-based diagnosis. Findings remained similar when the administrative definitions were compared to participant reported physician diagnoses in 2014 , ten years later.

Overall, the prevalence of depression varied depending on the definition used and the time period captured (Table 4). Lifetime prevalence was highest for the CIDI-based diagnosis of depression, which includes episodes of depression regardless of whether medical care was sought or not. Lifetime prevalence was lowest for the participant report of physician-diagnosed depression. Ten years later the prevalence based on administrative data similarly increased nearly $9 \%$.

Anxiety Disorders

As compared to a CIDI diagnosis of anxiety disorder, the anxiety-A definition had poor sensitivity $(30 \%)$ but good specificity ( $88 \%)$ (Table 5). When compared to participant report of physiciandiagnosed anxiety concurrent with the CIDI, sensitivity improved by $12.1-26.1 \%$, with only slight declines in specificity. When the anxiety-B definition was used, the sensitivity as compared to a CIDI diagnosis was $19.3 \%$ higher than for the other administrative definition, and as compared to a selfreported diagnosis was $15.3 \%$ higher. However, the gain in sensitivity was associated with a loss of specificity. Agreement between the administrative definitions and the various reference standards was 
fair. Findings remained similar when the administrative definitions were compared to self-reported diagnoses in 2014, ten years later.

Depending on the definition used, the prevalence of anxiety varied (Table 4). At the time the CIDI was administered, the prevalence was highest for administrative definition B and was lowest based on the participant report of physician-diagnosed anxiety. Ten years later, the self-reported prevalence of anxiety increased by $6 \%$, while the prevalence based on administrative data without using prescription claims increased by $6.7 \%$ and by nearly $13 \%$ using prescription claims.

\section{Depression or Anxiety Disorder}

As compared to a CIDI diagnosis of depression and/or anxiety disorder, the depression and/or anxietyA definition had poor sensitivity (45\%) but good specificity (89\%), consistent with the observations for the definitions of depression and anxiety (Table 6). When compared to participant report of physiciandiagnosed anxiety, sensitivity improved by $24.4 \%$, with a slight drop in specificity $(<5 \%)$. When the depression and/or anxiety-B definition was used, the sensitivity as compared to a CIDI diagnosis was similar as for the other administrative definition, and as compared to a self-reported diagnosis. Agreement between the administrative definitions and the various reference standards was fair to moderate; agreement was lowest with the CIDI-based diagnosis.

As expected, the combined prevalence of depression and/or anxiety) was higher than that of depression or anxiety alone (Table 4). The prevalence of depression or anxiety was highest based on the CIDI definition, and lowest based on participant report of physician diagnosis. The self-reported prevalence 
of depression or anxiety was about $10 \%$ higher ten years later, while the prevalence using administrative definitions rose $8.7-10.2 \%$ depending on the definition used.

\section{Misclassification Bias}

Based on a graphic analysis of misclassification basis, the administrative case definitions for depression showed misclassification of less than $3.2 \%$ in the expected range of prevalence for depression in IBD (20-30\%), as compared to participant report of physician diagnoses (Supplemental Figures 1-2). They appeared to underestimate prevalence relative to the CIDI to a greater degree, but this was expected given that the CIDI also captures those who have not interacted with the medical services system for diagnosis or treatment. The pattern of findings was similar for the anxiety definitions although the degree of misclassification was greater.

\section{Discussion}

Although depression and anxiety disorders are common in IBD, and their adverse effects on outcomes are increasingly recognized, few population-based estimates of the prevalence of depression or anxiety disorders exist due to the challenges of accurately assessing these comorbidities on a large scale. Most prior studies evaluating the incidence and prevalence of psychiatric comorbidity in IBD used clinicbased or small community samples.(3) Administrative health data offer a cost-effective means of estimating population-based rates, without the difficulties of recall bias posed by interviews(19) or questionnaires. In chronic diseases, comorbidities may be underreported in administrative data due to 
coding biases.(20) Therefore we tested administrative definitions developed in another chronic immune-mediated disease, MS, likely to face similar potential coding biases.

Both of our administrative case definitions for depression showed moderate agreement with diagnoses of depression based on the CIDI, which clinically assessed lifetime depression rates; there was slightly better agreement with participant reported physician diagnoses of depression. The performance of the depression case definitions in the IBD population was similar to that observed in the MS population in which these administrative definitions were developed. In the MS population, the administrative definition of depression with prescription claims data showed moderate agreement with diagnoses of depression based on medical records $(\kappa=0.49)$, while the definition without prescription claims showed moderate agreement with participant reported physician-based diagnoses $(\kappa=0.53) .(12,21)$ Similarly, West et al. reported a moderate level of agreement between an administrative definition and medical records $(\kappa=0.54)$ in Saskatchewan, however the validation cohort was selected from a pharmaceutical database based on the use of antidepressants.(11) In the general Manitoba population, agreement between a CIDI-based diagnosis of depression and an alternate administrative definition that used hospital, physician and prescription claims was lower than we observed $(\kappa=0.26) .(10)$ For anxiety, we found only fair agreement between the administrative case definitions and diagnoses of anxiety based on either the CIDI or participant report of physician diagnosis. The CIDI has been criticized for overdiagnosing anxiety, but most of those diagnosed have high rates of comorbidity and role impairment, supporting its validity.(22) Our findings were similar to those in MS in which agreement was only fair between the administrative definitions of anxiety and diagnoses of anxiety based on medical records or participant report of physician-based diagnoses $(\kappa=0.23-0.26)$. We could not identify any other case definitions for anxiety that have been validated at the individual level. 
Unlike case definitions for common, readily diagnosed medical conditions such as hypertension, it has been difficult to develop robust case definitions for depression and anxiety that are valid at the individual and population levels.(10,23) This likely reflects several factors including lack of specificity of 3-digit ICD codes, comorbidity between depression and anxiety, and variability of coding practices by health care providers. The use of reference standards that are broader or narrower in their capture of diagnoses than administrative data may also reduce the apparent concordance between data sources. Administrative data will only capture health conditions for which medical services are sought, and thus may be considered to provide "diagnosed" or "treated" prevalence estimates, and will be lower than estimates based on diagnostic interviews which identify disease irrespective of whether the condition was diagnosed, and treatment was sought. The lower concordance between administrative definitions and our reference standards for anxiety than for depression may be because persons with anxiety disorders seek treatment less often than those with depression,(24) although unmet treatment needs remain high for both disorders. $(25,26)$ Further, administrative data only captures information on care provided by physicians or in hospitals, therefore depression and anxiety treated by clinical psychologists or other non-physician mental health providers will not be captured. Despite these limitations, at the population level, the prevalence estimates of depression and anxiety based on administrative data show similar changes over time to those based on participant reported physician diagnoses.

Regardless of the definitions used in this study, the prevalence of depression in our IBD cohort was elevated compared to the general population. Based on the CIDI, major depression affects $16.2 \%(15.1$ $17.3 \%$ ) of the general population over a lifetime.(27) In comparison, the lifetime prevalence of 
depression of $29.3 \%$ in the IBD cohort based on the CIDI was nearly twice as high. Anxiety disorders affect $28.8 \%$ of the general population over a lifetime,(28) similar to what was estimated in our cohort based on the CIDI (31.2\%).

Strengths of this study included the use of a population-based validation cohort, multiple reference measures for depression and anxiety, and availability of reference measures at multiple points in time. While administrative data have limitations, diagnoses based on self-report and the CIDI rely on recall of past episodes. Our sample was not large enough to evaluate whether performance of the administrative definitions differed by participant characteristics. We tested administrative definitions developed in an MS population which offers the opportunity to conduct comparative studies across these diseases. It is possible that we could have improved upon the performance of these definitions by modifying them. Specifically, a review of medications included in the case definitions ('B') that used prescription claims would be worthwhile. We excluded amitriptyline, nortriptyline and buspirone because they are used off-label in MS. The first two of these therapies may also be used off-label in IBD for pain management as well, along with desipramine.(17) Failure to exclude desipramine could have reduced the specificity of the case definitions, but none of the other medications included are used off-label in IBD. Excluding buspirone could have reduced sensitivity. However, the performance of these definitions appears to be as good or better than other published definitions. Future work should evaluate whether IBD-specific definitions which have superior performance can be developed.

Our findings suggest that administrative data may be useful for population-level surveillance of depression and anxiety in IBD. If anxiety is an outcome of interest use of a combined definition of depression and anxiety may be preferred. Prescription claims data do not improve performance of 
administrative data for identifying these conditions. While the data may underestimate psychiatric comorbidity in IBD, the definitions are sufficiently robust for studies evaluating the association between depression and anxiety and health care utilization and outcomes in IBD.

\section{Acknowledgement}

This study was funded by the Canadian Institutes of Health Research (THC-135234) a Don Paty Career Development Award from the MS Society of Canada (to RAM), the Bingham Chair in Gastroenterology (to CNB). We would like to acknowledge the members of the CIHR team on "Defining the burden and managing the effects of psychiatric comorbidity in chronic immunoinflammatory disease": Dr. Ruth Ann Marrie, MD, PhD (University of Manitoba), Dr. Charles Bernstein, MD (University of Manitoba), Dr. Lindsay Berrigan, PhD (St. Francis Xavier University), Dr. James Bolton, MD (University of Manitoba), Dr. John Fisk, PhD (Dalhousie University), Dr. Lesley Graff, PhD (University of Manitoba), Dr. Carol Hitchon, MD, MSc (University of Manitoba), Dr. Alan Katz, MB, ChB (University of Manitoba), Dr. Lisa Lix, PhD (University of Manitoba), Dr. James Marriot, MD, MSc (University of Manitoba), Dr. Scott Patten, MD, PhD (University of Calgary), Dr. Jitender Sareen, MD (University of Manitoba), Dr. John Walker, PhD (University of Manitoba), Dr. Ryan Zarychanski, MD, MSc (University of Manitoba), Dr. Alexander Singer, MD (University of Manitoba), Dr. Christine Peschken, MD, MSc (University of Manitoba), Dr. Renee El-

Gabalawy, PhD (University of Manitoba). The funding source(s) had no role in the study design, collection, analysis or interpretation of the data, nor in the decision to submit the article for publication. The results and conclusions presented are those of the authors. No official endorsement by Manitoba Health is intended or should be inferred. Data were provided under project (HIPC \# 2013/14-03) 


\section{Competing interests}

All authors have completed the Unified Competing Interest form at http://www.icmje.org/coi_disclosure.pdf and declare that:

Ruth Ann Marrie has conducted clinical trials for Sanofi Aventis.

Charles Bernstein has consulted to Abbvie Canada, Janssen Canada, Pfizer Canada, Shire Canada, Takeda Canada, and has received unrestricted educational grants from Abbvie Canada, Janssen Canada, Shire Canada, and Takeda Canada. He has been on speaker's bureau of Abbvie Canada and Shire Canada

Spouses, partners, or children of the authors have no competing interests relevant to the submitted work.

There are no other non-financial interests that may be relevant to the submitted work.

The other authors have no competing interests to report' 
Marrie/ 17

\section{References}

1. Kaplan GG. The global burden of IBD: from 2015 to 2025. Nat Rev Gastroenterol Hepatol. 2015;12:720-727

2. Bernstein CN, Wajda A, Blanchard JF. The clustering of other chronic inflammatory diseases in inflammatory bowel disease: a population-based study. Gastroenterology. 2005;129:827-836

3. Graff LA, Walker JR, Bernstein CN. Depression and anxiety in inflammatory bowel disease: a review of comorbidity and management. Inflamm Bowel Dis. 2009;15:1105-1118

4. Walker JR, Ediger JP, Graff LA, et al. The Manitoba IBD cohort study: a population-based study of the prevalence of lifetime and 12-month anxiety and mood disorders. American Journal of Gastroenterology. 2008;103:1989-1997

5. Mittermaier C, Dejaco C, Waldhoer T, et al. Impact of depressive mood on relapse in patients with inflammatory bowel disease: a prospective 18-month follow-up study. Psychosomatic Medicine. 2004;66:79-84

6. Israeli E, Graff LA, Clara I, et al. Low prevalence of disability among patients with inflammatory bowel diseases a decade after diagnosis. Clin Gastroenterol Hepatol. 2014;12:1330-1337 e1332

7. Faust AH, Halpern LF, Danoff-Burg S, et al. Psychosocial Factors Contributing to Inflammatory Bowel Disease Activity and Health-Related Quality of Life. Gastroenterol Hepatol (N Y). 2012;8:173-181

8. Mohr DC, Goodkin DE, Likosky W, et al. Treatment of depression improves adherence to interferon beta-1b therapy for multiple sclerosis. Archives of Neurology. 1997;54:531-533

9. Patten S. Integrating data from clinical and administrative databases in pharmacoepidemiological research. Can J Clin Pharmacol. 1998;5:92-97

10. Martens P, Fransoo R, McKeen N, et al. Patterns of regional mental illness disorder diagnoses and service use in Manitoba: A population-based study. 2004. Available at: mchpappserv.cpe.umanitoba.ca/reference/mental.health.pdf

11. West SL, Richter A, Melfi CA, et al. Assessing the Saskatchewan database for outcomes research studies of depression and its treatment. J Clin Epidemiol. 2000;53:823-831

12. Marrie RA, Fisk JD, Yu BN, et al. Mental comorbidity and multiple sclerosis: validating administrative data to support population-based surveillance. BMC Neurology. 2013;13:16 13. Samkoff LM, Goodman AD. Symptomatic Management in Multiple Sclerosis. Neurologic Clinics. 2011;29:449-463

14. Longobardi T, Walker J, Graff L, et al. Health service utilization in IBD: Comparison of selfreport and administrative data. BMC Health Services Research. 2011;11:137

15. Horton M, Rudick RA, Hara-Cleaver C, et al. Validation of a Self-Report Comorbidity Questionnaire for Multiple Sclerosis. Neuroepidemiology. 2010;35:83-90

16. Landis JR, Koch GG. The measurement of observer agreement for categorical data. Biometrics. 1977;33:159-174

17. Docherty MJ, Jones RC, 3rd, Wallace MS. Managing pain in inflammatory bowel disease. Gastroenterol Hepatol (N Y). 2011;7:592-601

18. Kleinbaum D, Kupper L, Morgenstern H. Information bias. Epidemiologic Research: Principles and Quantitative Methods. New York: Van Nostrand Reinhold; 1982:220-241

19. Haro JM, Arbabzadeh-Bouchez S, Brugha TS, et al. Concordance of the Composite International Diagnostic Interview Version 3.0 (CIDI 3.0) with standardized clinical assessments in the 
WHO World Mental Health Surveys. International Journal of Methods in Psychiatric Research. 2006;15:167-180

20. Elixhauser A, Steiner C, Harris DR, et al. Comorbidity measures for use with administrative data. Medical Care. 1998;36:8-27

21. Marrie RA, Fisk JD, Stadnyk KJ, et al. Performance of administrative case definitions for comorbidity in multiple sclerosis in Manitoba and Nova Scotia. Chronic Dis Inj Can. 2014;34:145-153 22. Ruscio AM, Brown TA, Chiu WT, et al. Social fears and social phobia in the USA: results from the National Comorbidity Survey Replication. Psychol Med. 2008;38:15-28

23. Kisely S, Lin E, Gilbert C, et al. Use of administrative data for the surveillance of mood and anxiety disorders. Australian and New Zealand Journal of Psychiatry. 2009;43:1118-1125

24. Wang PS, Angermeyer M, Borges G, et al. Delay and failure in treatment seeking after first onset of mental disorders in the World Health Organization's World Mental Health Survey Initiative. World Psychiatry. 2007;6:177-185

25. Alonso J, Codony M, Kovess V, et al. Population level of unmet need for mental healthcare in Europe. Br J Psychiatry. 2007;190:299-306

26. Mojtabai R. Unmet need for treatment of major depression in the United States. Psychiatr Serv. 2009;60:297-305

27. Kessler RC, Berglund P, Demler O, et al. The epidemiology of major depressive disorder:

Results from the National Comorbidity Survey Replication (NCS-R). JAMA. 2003;289:3095-3105

28. Kessler RC, Berglund P, Demler O, et al. Lifetime prevalence and age-of-onset distributions of DSM-IV disorders in the National Comorbidity Survey Replication. Archives of General Psychiatry. 2005;62:593-602 
Table 1. Administrative Case Definitions for Depression and Anxiety Developed Initially for Multiple Sclerosis

\begin{tabular}{|c|c|c|c|c|c|}
\hline \multirow[t]{2}{*}{ Comorbidity } & \multicolumn{2}{|c|}{ Case Definition } & \multicolumn{2}{|l|}{ Diagnostic Codes } & \multirow{2}{*}{$\begin{array}{c}\text { Anatomic Therapeutic } \\
\text { Chemical Classification } \\
\text { System Code }\end{array}$} \\
\hline & $\begin{array}{l}\text { No. Years } \\
\text { of Data }\end{array}$ & $\begin{array}{l}\text { No. and type of } \\
\text { claims }\end{array}$ & ICD-9-CM & ICD-10-CA & \\
\hline \multicolumn{6}{|c|}{ Case Definition A- without Prescription Claims } \\
\hline Depression & 2 & $\geq 1 \mathrm{H}$ or $\geq 4 \mathrm{P}$ & $\begin{array}{c}296.2,296.3,298.0 \\
300.4,311\end{array}$ & F32, F33, F34 & \\
\hline Anxiety disorder & 2 & $\geq 1 \mathrm{H}$ or $\geq 3 \mathrm{P}$ & $300.0,300.2$ & F40, F41 & \\
\hline $\begin{array}{l}\text { Depression or } \\
\text { anxiety disorder }\end{array}$ & 2 & $\geq 1 \mathrm{H}$ or $\geq 5 \mathrm{P}$ & $\begin{array}{c}296.2,296.3,298.0 \\
300.4,311,300.0,300.2\end{array}$ & $\begin{array}{l}\text { F32, F33, F34 } \\
\text { F40, F41 }\end{array}$ & \\
\hline \multicolumn{6}{|c|}{ Case Definition B- with Prescription Claims } \\
\hline Depression & 2 & $\begin{array}{l}\geq 1 \mathrm{H} \text { or } \geq 5 \mathrm{P} \text { OR } \\
(\geq 1 \mathrm{P} \mathrm{AND} \geq 7 \mathrm{Rx})\end{array}$ & $296.2,296.3,298.0,300.4,311$ & F32, F33, F34 & $\begin{array}{c}\text { Antidepressants including } \\
\text { N06AA01, N06AA02, } \\
\text { N06AA04, N06AA11, } \\
\text { N06AA12, N06AA17, } \\
\text { N06AA21, N06AB03, } \\
\text { N06AB04, N06AB05, } \\
\text { N06AB06 } \\
\text { N06AB08, N06AB10, } \\
\text { N06AF03, N06AF04, } \\
\text { N06AG02, N06AX06, } \\
\text { N06AX11, N06AX16, } \\
\text { N06AX21, N06AX23 }\end{array}$ \\
\hline Anxiety & 2 & $\begin{array}{l}\geq 1 \text { H or } \geq 2 \text { P OR } \\
(\geq 1 \text { P AND } \geq 2 \mathrm{Rx})\end{array}$ & $300.0,300.2$ & F40, F41 & \\
\hline $\begin{array}{l}\text { Depression or } \\
\text { anxiety }\end{array}$ & 2 & $\begin{array}{l}\geq 1 \text { H or } \geq 5 \text { P OR } \\
(\geq 1 \text { P AND } \geq 4 \text { Rx })\end{array}$ & $\begin{array}{c}296.2,296.3,298.0,300.4 \\
311,300.0,300.2\end{array}$ & $\begin{array}{l}\text { F32, F33, F34 } \\
\text { F40, F41 }\end{array}$ & $\begin{array}{c}\text { Anxiolytics including } \\
\text { N05AB12 (Alprazolam), } \\
\text { N05AB06 (Lorazepam) }\end{array}$ \\
\hline
\end{tabular}


Table 2. Characteristics of Study Participants $(\mathrm{N}=266)$

\begin{tabular}{lc}
\hline Characteristic & Statistic \\
\hline Crohn's Disease, n (\%) & $140(52.6)$ \\
Female, n (\%) & $164(61.6)$ \\
Age at IBD diagnosis (years), mean (SD) & $35.6(13.8)$ \\
Age at CIDI administration (years), mean (SD) & $42.1(13.9)$ \\
Urban residence, n (\%) & $179(67.3)$ \\
\hline
\end{tabular}


Table 3. Comparison of Administrative Definitions of Depression and Clinical Cohort Definitions of Depression

\begin{tabular}{|c|c|c|c|c|c|}
\hline Reference Standard & $\begin{array}{c}\text { Sensitivity } \\
(95 \% \text { CI) }\end{array}$ & $\begin{array}{l}\text { Specificity } \\
\text { (95\% CI) }\end{array}$ & $\begin{array}{c}\text { PPV } \\
(95 \% \text { CI })\end{array}$ & $\begin{array}{c}\text { NPV } \\
(95 \% \text { CI })\end{array}$ & $\begin{array}{c}\text { Kappa } \\
(95 \% \text { CI })\end{array}$ \\
\hline \multicolumn{6}{|l|}{ Depression- A Definition (without prescription data) } \\
\hline CIDI diagnosis & $\begin{array}{c}50.0 \\
(38.9,61.1)\end{array}$ & $\begin{array}{c}88.8 \\
(84.3,93.3)\end{array}$ & $\begin{array}{c}65.0 \\
(52.9,77.1)\end{array}$ & $\begin{array}{c}81.1 \\
(75.7,86.4)\end{array}$ & $\begin{array}{c}0.42 \\
(0.29,0.54)\end{array}$ \\
\hline Participant reported physician diagnosis at time of CIDI & $\begin{array}{c}76.6 \\
(64.5,88.7)\end{array}$ & $\begin{array}{c}89.0 \\
(84.9,93.2)\end{array}$ & $\begin{array}{c}60.0 \\
(47.6,72.4)\end{array}$ & $\begin{array}{c}94.7 \\
(91.6,97.7)\end{array}$ & $\begin{array}{c}0.59 \\
(0.47,0.71)\end{array}$ \\
\hline Participant reported physician diagnosis as of 2014 & $\begin{array}{c}73.5 \\
(63.0,84.0)\end{array}$ & $\begin{array}{c}84.3 \\
(79.3,89.4)\end{array}$ & $\begin{array}{c}61.7 \\
(51.1,72.3)\end{array}$ & $\begin{array}{c}90.3 \\
(86.0,94.5)\end{array}$ & $\begin{array}{c}0.54 \\
(0.43,0.66)\end{array}$ \\
\hline \multicolumn{6}{|l|}{ Depression-B Definition (with prescription data) } \\
\hline CIDI diagnosis & $\begin{array}{c}47.4 \\
(36.3,58.5)\end{array}$ & $\begin{array}{c}88.8 \\
(84.3,93.3)\end{array}$ & $\begin{array}{c}63.8 \\
(74.9,85.7)\end{array}$ & $\begin{array}{c}80.3 \\
(74.9,85.7)\end{array}$ & $\begin{array}{c}0.39 \\
(0.27,0.51)\end{array}$ \\
\hline Participant reported physician diagnosis at time of CIDI & $\begin{array}{c}70.2 \\
(57.1,83.3)\end{array}$ & $\begin{array}{c}88.6 \\
(84.4,92.8)\end{array}$ & $\begin{array}{c}56.9 \\
(44.1,69.6)\end{array}$ & $\begin{array}{c}93.3 \\
(90.0,96.7)\end{array}$ & $\begin{array}{c}0.54 \\
(0.41,0.66)\end{array}$ \\
\hline
\end{tabular}

$\mathrm{CIDI}=$ Composite International Diagnostic Interview, $\mathrm{PPV}=$ positive predictive value, NPV = negative predictive value 
Table 4. Lifetime Prevalence (Percent) of Depression and Anxiety According to Differing Data Sources and Definitions $(\mathrm{N}=266)$

\begin{tabular}{|c|c|c|c|}
\hline Method & $\begin{array}{c}\text { Depression } \\
\text { Percent } \\
(95 \% \text { CI }) \\
\end{array}$ & $\begin{array}{l}\text { Anxiety } \\
\text { Percent } \\
(95 \% \text { CI }) \\
\end{array}$ & $\begin{array}{c}\text { Anxiety or Depression } \\
\text { Percent } \\
(95 \% \text { CI }) \\
\end{array}$ \\
\hline \multicolumn{4}{|l|}{ Reference Standard } \\
\hline CIDI diagnosis & $\begin{array}{c}29.3 \\
(24.2,35.1)\end{array}$ & $\begin{array}{c}31.2 \\
(25.9,37.0)\end{array}$ & $\begin{array}{c}44.7 \\
(38.9,50.7)\end{array}$ \\
\hline \multicolumn{4}{|l|}{ Comparison Standard Applied at Time of CIDI } \\
\hline Participant-reported physician diagnosis & $\begin{array}{c}17.7 \\
(13.6,22.7)\end{array}$ & $\begin{array}{c}9.7 \\
(6.8,13.9)\end{array}$ & $\begin{array}{c}19.9 \\
(15.6,25.1)\end{array}$ \\
\hline Definition A & $\begin{array}{c}22.5 \\
(17.9,27.9)\end{array}$ & $\begin{array}{c}17.7 \\
(13.5,22.7)\end{array}$ & $\begin{array}{c}26.3 \\
(21.4,31.9)\end{array}$ \\
\hline Definition B & $\begin{array}{c}21.8 \\
(17.3,27.1)\end{array}$ & $\begin{array}{c}31.9 \\
(26.6,37.8)\end{array}$ & $\begin{array}{c}28.9 \\
(23.8,34.7)\end{array}$ \\
\hline \multicolumn{4}{|l|}{ Comparison Standard Applied as of 2014} \\
\hline Participant-reported physician diagnosis & $\begin{array}{c}25.5 \\
(20.7,31.1)\end{array}$ & $\begin{array}{c}15.8 \\
(11.9,20.6)\end{array}$ & $\begin{array}{c}29.7 \\
(24.5,35.4)\end{array}$ \\
\hline Participant-reported physician diagnosis + treated in prior 10 years & $\begin{array}{c}20.7 \\
(16.2,25.9)\end{array}$ & $\begin{array}{c}13.1 \\
(9.6,17.7)\end{array}$ & $\begin{array}{c}24.8 \\
(20.0,30.3)\end{array}$ \\
\hline Definition A & $\begin{array}{c}30.4 \\
(25.2,36.2)\end{array}$ & $\begin{array}{c}24.4 \\
(19.7,29.9)\end{array}$ & $\begin{array}{c}35.0 \\
(29.5,40.9)\end{array}$ \\
\hline Definition B & $\begin{array}{c}30.4 \\
(25.2,36.2)\end{array}$ & $\begin{array}{c}44.7 \\
(38.9,50.7)\end{array}$ & $\begin{array}{c}39.1 \\
(33.4,45.1)\end{array}$ \\
\hline
\end{tabular}

'A' administrative definitions do not include prescription claims; 'B' administrative definitions include prescription claims 
Table 5. Performance of Anxiety Algorithms

\begin{tabular}{|c|c|c|c|c|c|}
\hline & $\begin{array}{c}\text { Sensitivity } \\
(95 \% \text { CI }) \\
\end{array}$ & $\begin{array}{c}\text { Specificity } \\
(95 \% \text { CI }) \\
\end{array}$ & $\begin{array}{c}\text { PPV } \\
(95 \% \text { CI })\end{array}$ & $\begin{array}{c}\text { NPV } \\
(95 \% \text { CI })\end{array}$ & $\begin{array}{c}\text { Kappa } \\
(95 \% \text { CI }) \\
\end{array}$ \\
\hline \multicolumn{6}{|l|}{ Anxiety-A Definition (without prescription data) } \\
\hline CIDI diagnosis & $\begin{array}{c}30.1 \\
(20.2,40.0)\end{array}$ & $\begin{array}{c}88.0 \\
(83.3,92.7)\end{array}$ & $\begin{array}{c}53.2 \\
(38.9,67.4)\end{array}$ & $\begin{array}{c}73.5 \\
(67.7,79.4)\end{array}$ & $\begin{array}{c}0.21 \\
(0.083,0.33)\end{array}$ \\
\hline Self-reported diagnosis at time of CIDI & $\begin{array}{c}46.2 \\
(27.0,65.3)\end{array}$ & $\begin{array}{c}85.4 \\
(80.9,89.9)\end{array}$ & $\begin{array}{c}25.5 \\
(13.1,38.0)\end{array}$ & $\begin{array}{c}93.6 \\
(90.4,96.8)\end{array}$ & $\begin{array}{c}0.23 \\
(0.084,0.38)\end{array}$ \\
\hline Self-reported diagnosis as of 2014 & $\begin{array}{c}42.9 \\
(27.9,57.8)\end{array}$ & $\begin{array}{c}79.0 \\
(73.7,84.3)\end{array}$ & $\begin{array}{c}27.7 \\
(16.8,38.5)\end{array}$ & $\begin{array}{c}88.1 \\
(83.6,92.5)\end{array}$ & $\begin{array}{c}0.18 \\
(0.048,0.31)\end{array}$ \\
\hline Self-reported diagnosis as of 2014 and treated in last 10 years & $\begin{array}{c}45.7 \\
(29.2,62.2)\end{array}$ & $\begin{array}{c}78.8 \\
(73.5,84.1)\end{array}$ & $\begin{array}{c}24.6 \\
(14.1,35.1)\end{array}$ & $\begin{array}{c}90.5 \\
(86.5,94.6)\end{array}$ & $\begin{array}{c}0.18 \\
(0.05,0.31)\end{array}$ \\
\hline \multicolumn{6}{|l|}{ Anxiety-B Definition (with prescription data) } \\
\hline CIDI diagnosis & $\begin{array}{c}49.4 \\
(38.6,60.1)\end{array}$ & $\begin{array}{c}76.0 \\
(69.8,82.1)\end{array}$ & $\begin{array}{c}48.2 \\
(37.6,58.8)\end{array}$ & $\begin{array}{c}76.8 \\
(70.6,82.9)\end{array}$ & $\begin{array}{c}0.25 \\
(0.13,0.37)\end{array}$ \\
\hline Self-reported diagnosis at time of CIDI & $\begin{array}{c}61.5 \\
(42.8,80.2)\end{array}$ & $\begin{array}{c}71.3 \\
(65.5,77.0)\end{array}$ & $\begin{array}{c}18.8 \\
(10.5,27.1)\end{array}$ & $\begin{array}{c}94.5 \\
(91.1,97.8)\end{array}$ & $\begin{array}{c}0.16 \\
(0.056,0.27)\end{array}$ \\
\hline Self-reported diagnosis as of 2014 & $\begin{array}{c}76.2 \\
(63.3,89.0)\end{array}$ & $\begin{array}{c}61.2 \\
(54.8,67.5)\end{array}$ & $\begin{array}{c}26.9 \\
(18.9,34.8)\end{array}$ & $\begin{array}{c}93.2 \\
(89.1,97.3)\end{array}$ & $\begin{array}{c}0.21 \\
(0.12,0.31)\end{array}$ \\
\hline Self-reported diagnosis as of 2014 and treated in last 10 years & $\begin{array}{c}80.0 \\
(66.7,93.2)\end{array}$ & $\begin{array}{c}60.6 \\
(54.3,66.9)\end{array}$ & $\begin{array}{c}23.5 \\
(15.9,31.1)\end{array}$ & $\begin{array}{c}95.2 \\
(91.8,98.7)\end{array}$ & $\begin{array}{c}0.20 \\
(0.11,0.29)\end{array}$ \\
\hline
\end{tabular}

CIDI = Composite International Diagnostic Interview, PPV = positive predictive value, NPV = negative predictive value 
Table 6. Performance of Combined Depression and/or Anxiety Algorithms

\begin{tabular}{|c|c|c|c|c|c|}
\hline & $\begin{array}{c}\text { Sensitivity } \\
(95 \% \text { CI }) \\
\end{array}$ & $\begin{array}{c}\text { Specificity } \\
(95 \% \text { CI }) \\
\end{array}$ & $\begin{array}{c}\text { PPV } \\
(95 \% \text { CI })\end{array}$ & $\begin{array}{c}\text { NPV } \\
(95 \% \text { CI })\end{array}$ & $\begin{array}{c}\text { Kappa } \\
(95 \% \text { CI })\end{array}$ \\
\hline \multicolumn{6}{|l|}{ Combined-A Definition (without prescription data) } \\
\hline CIDI diagnosis & $\begin{array}{c}45.4 \\
(36.4,54.3)\end{array}$ & $\begin{array}{c}89.1 \\
(80.8,91.9)\end{array}$ & $\begin{array}{c}77.1 \\
(67.3,87.0)\end{array}$ & $\begin{array}{c}66.8 \\
(60.2,73.4)\end{array}$ & $\begin{array}{c}0.35 \\
(0.25,0.46)\end{array}$ \\
\hline Participant reported physician diagnosis at time of CIDI & $\begin{array}{c}69.8 \\
(57.4,82.2)\end{array}$ & $\begin{array}{c}84.5 \\
(79.6,89.4)\end{array}$ & $\begin{array}{c}52.9 \\
(41.1,64.5)\end{array}$ & $\begin{array}{c}91.8 \\
(88.0,95.7)\end{array}$ & $\begin{array}{c}0.48 \\
(0.36,0.61)\end{array}$ \\
\hline Participant reported physician diagnosis as of 2014 & $\begin{array}{c}62.0 \\
(51.3,72.7)\end{array}$ & $\begin{array}{c}76.5 \\
(70.4,82.5)\end{array}$ & $\begin{array}{c}52.7 \\
(42.5,62.8)\end{array}$ & $\begin{array}{c}82.7 \\
(81.9,92.2)\end{array}$ & $\begin{array}{c}0.37 \\
(0.25,0.48)\end{array}$ \\
\hline \multicolumn{6}{|l|}{ Combined-B Definition (with prescription data) } \\
\hline CIDI diagnosis & $\begin{array}{c}47.9 \\
(38.9,56.9)\end{array}$ & $\begin{array}{c}86.4 \\
(80.8,91.9)\end{array}$ & $\begin{array}{c}74.0 \\
(64.2,83.8)\end{array}$ & $\begin{array}{c}67.2 \\
(60.5,73.9)\end{array}$ & $\begin{array}{c}0.35 \\
(0.25,0.46)\end{array}$ \\
\hline Participant reported physician diagnosis at time of CIDI & $\begin{array}{c}71.7 \\
(59.6,83.8)\end{array}$ & $\begin{array}{c}81.7 \\
(76.5,86.9)\end{array}$ & $\begin{array}{c}49.4 \\
(38.2,60.5)\end{array}$ & $\begin{array}{c}92.1 \\
(88.2,95.6)\end{array}$ & $\begin{array}{c}0.46 \\
(0.33,0.58)\end{array}$ \\
\hline
\end{tabular}

$\mathrm{CIDI}=$ Composite International Diagnostic Interview, PPV $=$ positive predictive value, NPV = negative predictive value 
Marrie/ 25 